\title{
Perilaku Berbagai Data Iklim Sebagai Input Tunggal untuk Model JST dari Evapotranspirasi Potensial Harian Penman-Monteith
}

\author{
Danayanti Azmi Dewi Nusantara ${ }^{1}$, Feriza Nadiar ${ }^{1}$, Mohamad Bagus Ansori ${ }^{2}$ \\ ${ }^{1}$ Jurusan Teknik Sipil, Fakultas Teknik, Universitas Negeri Surabaya - Kampus Ketintang, Surabaya \\ ${ }^{2}$ Departemen Teknik Sipil, Institut Teknologi Sepuluh Nopember - Kampus Sukolilo, Surabaya \\ e-mail: danayantinusantara@unesa.ac.id No. HP 082234784671
}

\begin{abstract}
ABSTRAK
Di Indonesia sebagai daerah yang memiliki iklim tropis, menghitung jumlah evapotranspirasi potensial (ETp) harian menjadi penting. Selain itu, ketika pada musim kemarau, laju ETp tumbuh menjadi signifikan untuk memverifikasi keseimbangan air. ETp berkembang menjadi sangat penting untuk kasus ketersediaan air seperti irigasi, pasokan air, tenaga air, dll. Model ETp dibentuk dari berbagai input data iklim yaitu kecepatan angin, kelembaban relatif, durasi radiasi matahari, suhu rata-rata, penguapan, dan curah hujan. Langkah pemodelannya panjang dan rumit. Penggunaan Jaringan Syaraf Tiruan (JST) sebagai pemodelan berbasis data untuk menyederhanakan proses pemodelan. Model JST dari ETp akan ditargetkan untuk mendekati ETp yang dihitung dengan Penman-Monteith. Penelitian ini bertujuan untuk mengetahui perilaku masing-masing data iklim sebagai input tunggal untuk model JST dari evapotranspirasi potensial. Nilai MSE dan nilai R pada proses validasi JST dapat menunjukkan bagaimana perbedaan antara hasil data iklim tertentu dengan set data iklim lengkap. Hasil dari penelitian ini adalah parameter data iklim kelembapan relatif menghasilkan model JST terbaik dengan input data iklim tunggal apabila dibandingkan dengan model JST yang dibangun dengan input tunggal parameter data iklim lainnya. Selain itu, menunjukkan bahwa kelembapan relatif sebagai input yang signifikan ke model ETp Penman-Monteith baik menggunakan JST maupun tidak.
\end{abstract}

Kata kunci : evapotranspirasi; JST; penman; iklim

ABSTRACT

In Indonesia, as a region that has a tropical climate, calculating the amount of daily potential evapotranspiration (PET) becomes essential. Also, when on the drought season, the rate of PET grows into significant to verify the water balance. The PET develops into crucial for water availability cases such as irrigation, water supply, bydropower, etc. The PET model established from various input of climate data that are wind speed, relative bumidity, the duration of solar radiation, average temperature, evaporation, and rainfall. The step of modeling is long and complicated. It is using Artificial Neural Network. (ANN) as data-driven modeling to simplifies the process of modeling PET. The ANN PET model will be targeted to approach the PET calculated with Penman-Monteith. This research aimed to know the behavior of each of the climate data as a single input to the ANN PET model. The MSE-value and R-value on the validation process of $A N N$ can show how the differential between the results of particular climate data to the full data set. The outcome of this research is the relative bumidity presents the best ANN model with a single input of climate data than others. Besides, it makes the relative humidity as a doubtless significantly input to the PET model even using ANN or not.

Keywords : evapotranspiration; ANN; penman; climate

\section{PENDAHULUAN}

Evapotranspirasi merupakan salah satu bagian dari siklus hidrologi yang harus selalu dipertimbangkan dalam menghitung keseimbangan air. Apalagi untuk segala sesuatu yang erat kaitannya dengan 
ketersediaan air. Misalnya dalam hal ketersediaan air baku, air untuk irigasi, air untuk operasional PLTA, air untuk tambak, dan sebagainya. Evapotranspirasi menjadi salah satu pengurang dari total aliran permukaan yang terjadi akibat hujan, selain adanya peresapan atau infiltrasi maupun perkolasi ke dalam tanah.

Evapotranspirasi adalah jumlah laju evaporasi dan transpirasi lebih sering digunakan daripada hanya menghitung evaporasi (penguapan di atas muka air). Sebagai pertimbangan lainnya, transpirasi juga terjadi pada daerah aliran sungai (DAS) yang permukaan lahannya tertutup dengan berbagai vegetasi. Untuk menghitung laju evaporasi aktual bisa digunakan alat seperti pan evaporasi, sedangkan untuk menghitung laju evapotranspirasi aktual pada suatu wilayah sulit dilakukan. Sehingga dalam perhitungan laju evapotranspirasi yang terjadi dilakukan pendekatan empiris, yang bisa disebut sebagai laju evapotranspirasi potensial (ETp).

Dalam beberapa tahun terakhir, sudah banyak metode untuk mengestimasi besarnya laju ETp. Salah satunya adalah metode Penman-Monteith (PM) yang dapat dilihat pada persaman (1) dibawah ini[1].

$$
E T p=\frac{0,08 \Delta\left(R_{n}-G\right)+\gamma \frac{900}{T+273} u_{2}\left(e_{s}-e_{a}\right)}{\Delta+\gamma\left(1+0,34 u_{2}\right)}
$$

Pada persamaan (1) laju ETp diestimasi dari beberapa data diantaranya radiasi matahari netto $(\mathrm{Rn})$, temperatur $(\mathrm{T})$, kecepatan angin pada ketinggian $2 \mathrm{~m}\left(\mathrm{u}_{2}\right)$, tekanan uap actual $\left(\mathrm{e}_{2}\right)$, dan tekanan uap jenuh $\left(\mathrm{e}_{\mathrm{s}}\right)$. Tidak semua data yang dibutuhkan tersebut sudah tersedia pada stasiun pencatatan data iklim yang ada di Indonesia. Contohnya, untuk data $e_{a}$ dan $e_{s}$ yang bisa didapatkan dengan membaca tabel yang sudah dikeluarkan oleh
PM. Data iklim yang tersedia di BMKG yang bisa digunakan untuk mengestimasi besarnya laju ETp dengan metode PM adalah temperatur harian rata-rata, kecepatan angin, kelembapan relatif, evaporasi, tinggi hujan, dan lama penyinaran matahari,

Sejak tahun 1960an, berawal dari Penman dan Monteith yang menemukan rumus empiris dalam mengestimasi laju ETp, metode tersebut tetap digunakan hingga saat ini [2]. Bahkan The United Nations Food and Agriculture Organization (FAO) merekomendasikan penggunaan metode Penman-Monteith (PM) sebagai standar perhitungan laju ETp [1]. Metode FAO-PM sudah terbukti cocok digunakan pada daerah beriklim tropis, tidak terkecuali di Indonesia [3]-[4][5].

Dalam menghitung laju ETp menggunakan metode FAO-PM, akan melalui proses yang cukup rumit. Metode ini membutuhkan beberapa data iklim. Sedangkan, beberapa data iklim yang dibutuhkan harus melalui asumsi dan estimasi. Hal ini dikarenakan tidak adanya pencatatan secara lengkap di stasiun BMKG di Indonesia. Sehingga penggunan pemodelan berbasis data-driven seperti Jaringan Saraf Tiruan (JST) diharapkan akan mempermudah proses yang rumit dan panjang tersebut.

JST sebagai model yang diinspirasi dari sistem biologi dari kecerdasan otak manusia. JST berkemampuan untuk mengklasifikasi dan mengenal suatu pola dengan melalui proses pembelajaran [6]. JST juga bisa digunakan dalam peramalan data yang akan datang berdasarkan proses learning dari data yang telah ada sebelumnya [7]-[8]. Aplikasi penerapan model JST 
untuk mengestimasi ETp juga sudah dilakukan dalam beberapa tahun terakhir di Indonesia [9]. Penelitian tersebut menunjukkan hasil yang cukup baik dibandingkan dengan perhitungan secara konvensional.

Kenyataan bahwa data iklim yang seharusnya digunakan untuk input model JST ETp FAO-PM sering kali tidak tersedia secara lengkap di beberapa daerah di negara berkembang seperti Indonesia, sedangkan estimasi laju ETp sangat dibutuhkan. Maka dalam penelitian ini akan dicari perilaku masing-masing dari data iklim tersebut jika menjadi input tunggal dari model JST. Data iklim yang mempunyai pengaruh signifikan pada model akan terlihat dan diharapkan parameter data tersebut selalu tersedia pada semua daerah yang membutuhkan data untuk mengestimasi laju ETp.

\section{METODE PENELITIAN}

Pemodelan JST dilakukan dengan menggunakan program bantu MATLAB. Pada MATLAB terdapat toolbox neural network yaitu NFTOOL (Neural Network Fitting Tool) yang dapat membantu proses pemodelan ETp dengan JST [10]-[11]. Langkah pertama adalah persiapan dan penetapan data input dan target model.

Penelitian ini dilakukan dengan menggunakan enam data klimatologi yaitu lama penyinaran matahari, evaporasi, tinggi hujan, kecepatan angin, kelembapan relatif, dan temperatur rata-rata sebagai input tunggal pada pemodelan JST. Semua data berupa data pencatatan harian pada stasiun BMKG Juanda Surabaya. Data klimatologi total yang digunakan masing-masing berjumlah 1095 data, yang terkumpul selama tiga tahun.
Dalam pemodelan JST selain diharuskan untuk menyiapkan variabel input, maka juga harus disiapkan variabel target. Target model ETp-JST disiapkan dengan menghitung ETp secara manual menggunakan metode FAO-PM. Sehingga proses perhitungan yang panjang dan komplek dari metode FAO-PM seperti menggunakan beberapa bacaan tabel ea dan es dikarenakan di Indonesia tidak tersedia data pencatatan langsungnya. Hal ini bertujuan supaya hasil model ETp-JST mendekati hasil ETp-FAO-PM.

Proses persiapan data pada model JST diakhiri dengan mengelompokkan data input maupun target ke dalam tiga kelompok data yaitu data training, validation, dan testing. Dalam melakukan pemodelan ini ditetapkan data training yang digunakan sebanyak $70 \%$ dari total jumlah data yaitu sebanyak 767 data. Sedangkan untuk data validation dan testing masing-masing sebanyak $15 \%$ dari total jumlah data yaitu sebanyak 164 data. Dasar dari proses penetapan pembagian prosentase data di atas adalah berdasarkan standar dari program bantu yang digunakan, untuk training harus $70 \%$ sehingga sisanya 30\% untuk validation dan testing.

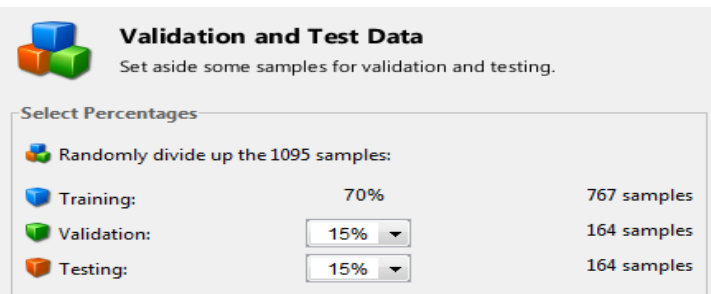

Gambar 1. Proses Pembagian Data Input Pemodelan ETp-JST (Sumber: Pemodelan)

Proses penetapan pembagian data training, validation, dan testing pada pemodelan dapat dilihat pada Gambar 1.

Pada pemodelan JST perlu adanya arsitektur model yang terdiri dari tiga nodes, 
yaitu: input, bidden, dan output. Penelitian ini bertujuan untuk mengetahui perilaku masing-masing data klimatologi sebagai input tunggal pada model, sehingga input model berupa satu data klimatologi. Akan ada enam arsitektur model seperti dijabarkan pada Tabel 1.

Tabel 1. Single Input Model JST - ETp

\begin{tabular}{cc}
\hline Nama Model & $\begin{array}{c}\text { Data Klimatologi sebagai Input } \\
\text { Tunggal }\end{array}$ \\
\hline 1A & Temperatur rata - rata $\left({ }^{\circ} \mathrm{C}\right)$ \\
1B & Kelembapan relatif $(\%)$ \\
1C & Kecepatan angin $(\mathrm{km} / \mathrm{jam})$ \\
1D & Tinggi hujan $(\mathrm{mm})$ \\
1E & Evaporasi $(\mathrm{mm})$ \\
1F & Lama penyinaran matahari (jam) \\
\hline
\end{tabular}

Untuk jumlah hidden nodes akan dilakukan trial mulai dari satu sampai dengan mendapatkan model terbaik dengan jumlah hidden nodes tertentu pada masing-masing model. Arsitektur model dapat dilihat pada Gambar 2 di bawah ini.

Proses selanjutnya adalah melakukan proses pembelajaran model JST dengan menggunakan Levenberg - Marquardt backpropagation. Pada tahap ini pemodelan berbasis data akan melakukan pembelajaran sendiri sampai berhenti. Pembelajaran otomatis berhenti saat secara keseluruhan model mengalami peningkatan kali sebagai indikasinya adalah pada peningkatan dari nilai MSE (Mean Square Error) pada data validasi sebanyak enam kali. Proses pelatihan model jaringan ditunjukkan pada Gambar 3 dengan contoh hasil ditunjukkan pada Gambar 4. Jika menginginkan hasil model yang mungkin lebih baik dapat dilakukan retrain.

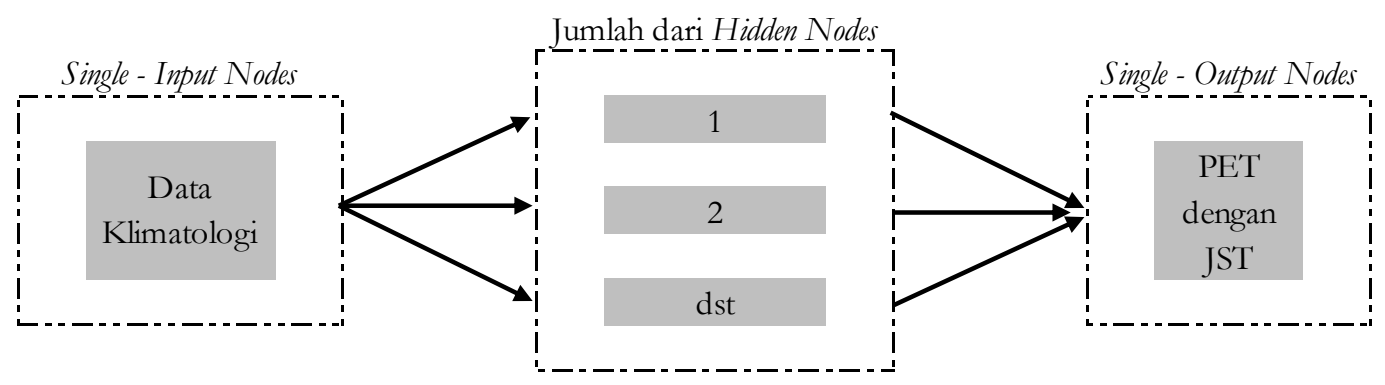

Gambar 2. Arsitektur Model JST - ETp dengan Single Input

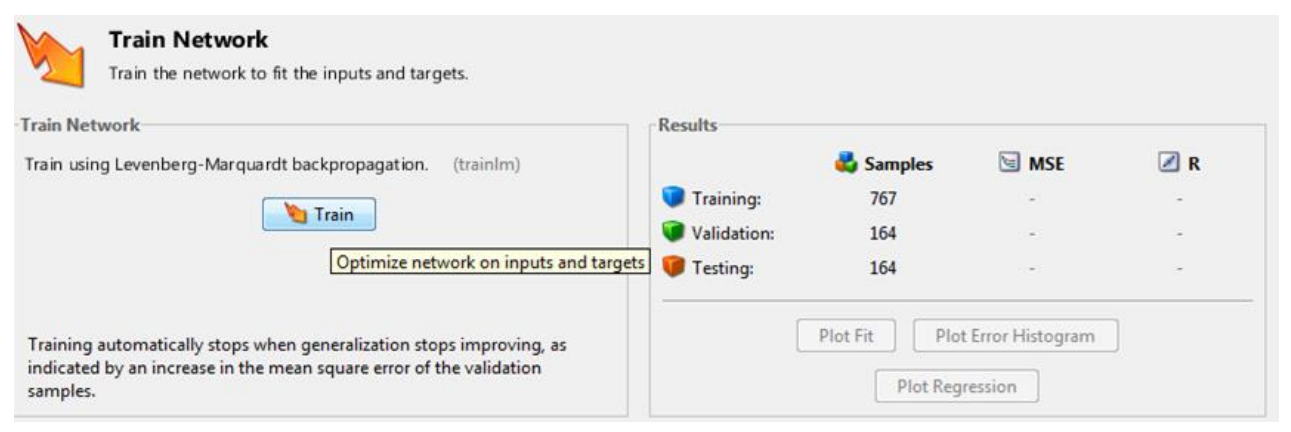

Gambar 3. Contoh Proses Pelatihan Model JST - ETp dengan Single Input (Sumber: Pemodelan) 


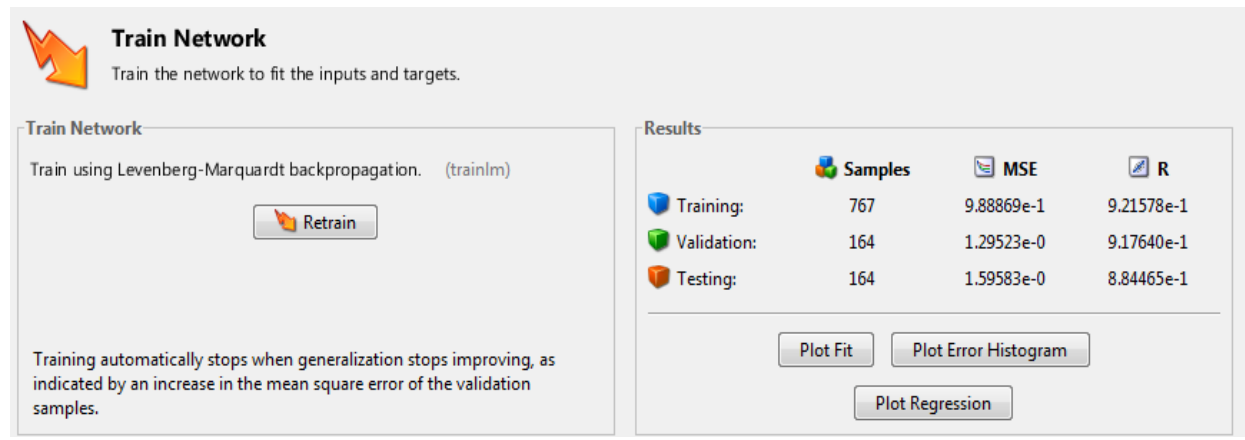

Gambar 4. Contoh Hasil Performa Model dan Retrain pada Model JST - ETp dengan Single Input (Sumber: Pemodelan

Dalam penelitian ini setiap arsitektur masing-masing model dilakukan pembatasan pelatihan sebanyak lima kali atau empat kali retrain sehingga dapat diambil model yang terbaik untuk arsitektur tersebut.

Model terbaik pada penelitian ini dapat diketahui dari proses validasi. Pada proses tersebut akan dibandingkan nilai MSE (Mean Square Error), apabila nilai MSE nya sama maka berikutnya dapat dilihat nilai $\mathrm{R}$ (Regression) yang dihasilkan oleh model. Untuk model terbaik nilai MSE-nya mendekati 0 yang berarti hampir tidak ada error, sedangkan nilai R-nya mendekati 1 yang menggambarkan adanya hubungan antara output dan target. Proses ini dapat digambarkan pada Gambar 5 berikut. Untuk contoh hasil performa model MSE dapat dilihat di Gambar 6 dan contoh hasil performa model $\mathrm{R}$ dapat dilihat di Gambar 7 berikut ini.

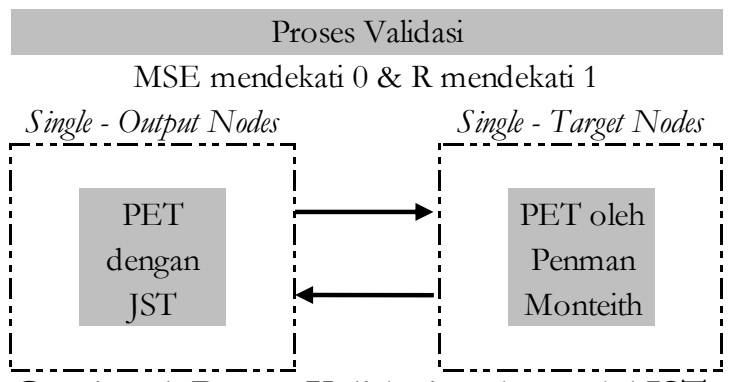

Gambar 5. Proses Validasi pada model JSTETp

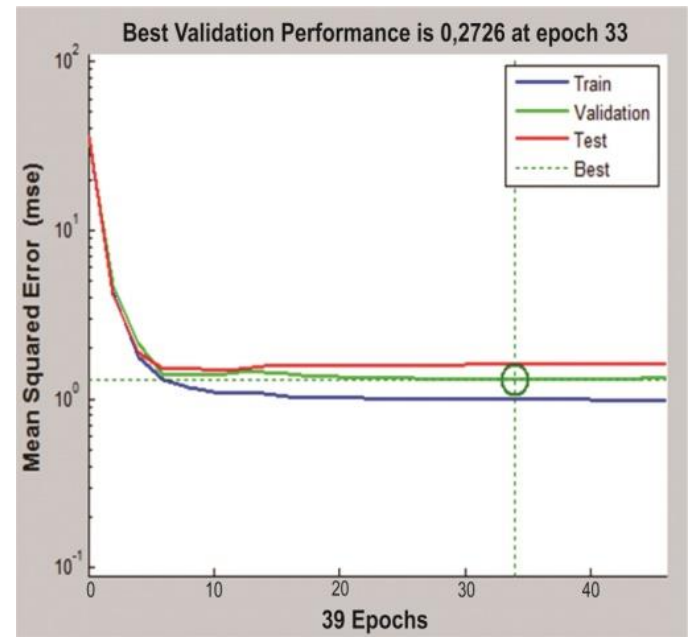

Gambar 6. Contoh Hasil Performa (MSE) pada Validation model JST-ETp (Sumber: Pemodelan)

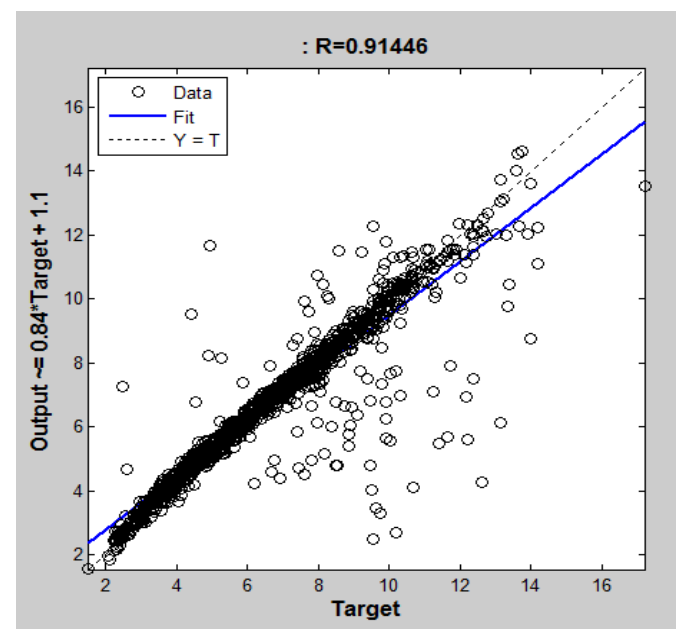

Gambar 7. Contoh Hasil Performa (R) pada Validation model JST-ETp (Sumber: Pemodelan) 


\section{HASIL DAN PEMBAHASAN}

Dalam penelitian terhadap enam model seperti yang sudah dijelaskan sebelumnya dilakukan analisa pada setiap performa MSE dan $\mathrm{R}$ masing-masing model. Arsitektur Model terbaik tiap model berbeda tergantung dari jumlah bidden nodes yang berbeda pada tiap modelnya.

Untuk Model 1A dengan input data klimatologi berupa temperatur rata-rata harian, arsitektur model terbaiknya adalah 1-11-1. Arsitektur model tersebut berarti 1input node, 11-bidden nodes, dan 1 output node. Performa model terbaik $1 \mathrm{~A}$ ini memiliki nilai MSE 4.05, yang merupakan nilai terendah diantara hasil performa MSE model 1A yang memiliki jumlah bidden nodes yang berbeda. Selanjutnya untuk nilai performa $\mathrm{R}$ model $1 \mathrm{~A}$ terbaik adalah 0.53 .

Model terbaik 1B memiliki arsitektur model terbaiknya adalah 1-6-1, sedangkan untuk Model 1C arsitektur model terbaiknya adalah 1-1-1. Dapat diketahui juga Model 1D, Model 1E, dan Model 1F memiliki arsitektur model terbaik yang sama yaitu 1-9-1.

Untuk hasil performa MSE dan $\mathrm{R}$ pada proses validasi Model 1B, Model 1C, Model 1D, Model 1E, dan Model 1F dapat dilihat secara keseluruhan pada Tabel 2 berikut ini.

Tabel 2. Hasil Performa $M S E$ dan $R$ pada Model ETp - JST

\begin{tabular}{|c|c|c|c|c|c|c|c|c|c|c|c|c|}
\hline \multirow{3}{*}{$\begin{array}{c}\text { Jumlah } \\
\text { Hidden } \\
\text { Nodes }\end{array}$} & \multicolumn{12}{|c|}{ Hasil Validasi pada Masing - Masing Model } \\
\hline & \multicolumn{2}{|c|}{$1 \mathrm{~A}$} & \multicolumn{2}{|c|}{$1 \mathrm{~B}$} & \multicolumn{2}{|c|}{$1 \mathrm{C}$} & \multicolumn{2}{|c|}{$1 \mathrm{D}$} & \multicolumn{2}{|c|}{$1 \mathrm{E}$} & \multicolumn{2}{|c|}{$1 F$} \\
\hline & $M S E$ & $\boldsymbol{R}$ & $M S E$ & $\boldsymbol{R}$ & MSE & $\boldsymbol{R}$ & $M S E$ & $\boldsymbol{R}$ & $M S E$ & $\boldsymbol{R}$ & $M S E$ & $\boldsymbol{R}$ \\
\hline 1 & 4.94 & 0.42 & 1.88 & 0.85 & 3.10 & 0.70 & 4.26 & 0.55 & 4.01 & 0.66 & 4.01 & 0.65 \\
\hline 2 & 5.62 & 0.43 & 1.87 & 0.83 & 4.17 & 0.60 & 3.97 & 0.59 & 4.48 & 0.57 & 4.10 & 0.57 \\
\hline 3 & 5.21 & 0.42 & 1.64 & 0.87 & 3.81 & 0.66 & 4.30 & 0.57 & 4.19 & 0.67 & 4.17 & 0.63 \\
\hline 4 & 4.76 & 0.55 & 2.12 & 0.84 & 3.74 & 0.73 & 4.30 & 0.61 & 4.51 & 0.60 & 4.07 & 0.63 \\
\hline 5 & 4.73 & 0.43 & 1.64 & 0.86 & 3.32 & 0.65 & 3.78 & 0.63 & 4.27 & 0.56 & 4.86 & 0.56 \\
\hline 6 & 4.71 & 0.54 & 1.47 & 0.88 & 3.30 & 0.66 & 4.01 & 0.62 & 3.97 & 0.57 & 4.14 & 0.58 \\
\hline 7 & 4.76 & 0.46 & 2.08 & 0.82 & 3.93 & 0.59 & 4.77 & 0.47 & 4.71 & 0.59 & 4.48 & 0.58 \\
\hline 8 & 4.79 & 0.48 & 1.66 & 0.85 & 3.95 & 0.61 & 4.11 & 0.51 & 4.13 & 0.56 & 4.08 & 0.53 \\
\hline 9 & 4.80 & 0.46 & 1.93 & 0.82 & 3.53 & 0.72 & 3.46 & 0.66 & 3.97 & 0.62 & 3.57 & 0.66 \\
\hline 10 & 4.45 & 0.51 & 2.30 & 0.82 & 3.46 & 0.67 & 3.97 & 0.53 & 4.87 & 0.48 & 4.02 & 0.49 \\
\hline 11 & 4.05 & 0.53 & & & & & 4.85 & 0.56 & 4.24 & 0.63 & 4.27 & 0.49 \\
\hline 12 & 5.19 & 0.49 & & & & & 4.45 & 0.59 & 4.70 & 0.49 & 4.82 & 0.54 \\
\hline
\end{tabular}

Setelah menentukan arsitektur model terbaik tiap model dengan input data klimatologi yang sama tetapi berlainan jumlah bidden nodes, maka selanjutnya membandingkan hasil performa MSE dan R model terbaik tersebut dengan model terbaik dari model yang berlainan input data klimatologi.
Dilihat dari hasil performa MSE-nya, Model 1B dengan input kelembapan relatif mempunyai nilai MSE 1.47, nilai tersebut merupakan nilai MSE paling rendah dibandingkan dengan lima model lainnya. Sama halnya dilihat dari hasil performa Rnya, model $1 \mathrm{~B}$ juga memiliki nilai $\mathrm{R}$ tertinggi yaitu 0.88 yang paling mendekati 1 . Dari analisa tersebut bisa disimpulkan 
kelembapan relatif jika sebagai input tunggal pada pemodelan ETp-JST menghasilkan performa model yang terbaik dengan arsitektur model terbaiknya adalah 1-6-1. Contoh hasil perbandingan data evapotranspirasi potensial pada proses validasi dan testing yang dihasilkan oleh model ETp-JST dengan target model ETpFAO-PM bisa dilihat pada gambar 8 .
Sedangkan data klimatologi tinggi hujan (Model 1D), evaporasi (Model 1E), dan lamanya penyinaran matahari (Model 1F) menunjukkan perilaku yang sama apabila digunakan sebagai input tunggal pada pemodelan ETp-JST. Hal ini ditunjukkan dengan hasil perforna yang cenderung sama dan arsitektur model terbaiknya juga sama.

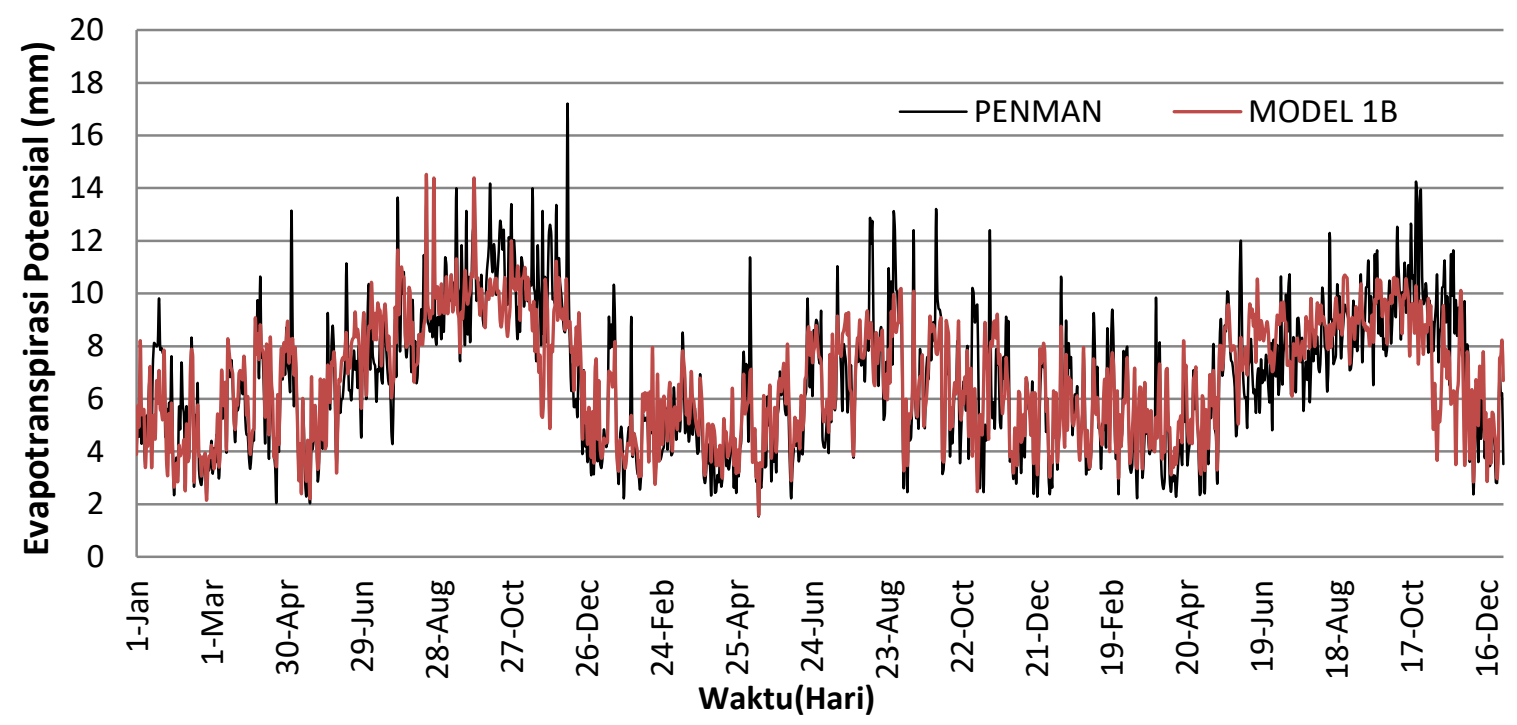

Gambar 8. ETp-JST Hasil Output Model 1B vs Target Etp-FAO-PM

Sumber : Pemodelan

\section{KESIMPULAN}

Hasil dari penelitian ini adalah kelembapan relatif sebagai input tunggal pada model JST memberikan hasil model terbaik dibandingkan dengan input tunggal data klimatologi yang lain. Kelembapan relatif menjadi data klimatologi yang sangat signifikan dalam mengetimasi ETp. Sehingga diharapkan data kelembapan relatif, minimal dapat tersedia secara lengkap di semua daerah yang membutuhkan data untuk mengestimasi ETp. Model ETp-JST (1B) yang dihasilkan akan sangat bermanfaat ketika terjadi keterbatasan data klimatologi. Dengan menggunakan model tersebut, besarnya evapotranspirasi potensial pada suatu daerah tetap dapat diestimasi hanya dengan mengetahui data kelembapan relatifnya.

Sebaliknya untuk model ETp-JST dengan input tunggal data klimatologi temperatur rata-rata harian, memberikan hasil performa terburuk dari kelima model lainnya. Sehingga penggunan data klimatologi temperatur rata-rata harian untuk menghitung ETp secara tunggal kurang disarankan. Selain nilai MSE-nya paling tinggi, juga nilai $\mathrm{R}$-nya paling rendah dibandingkan dengan model yang lain. 


\section{PENGHARGAAN}

Terima kasih kepada pihak BMKG Juanda Surabaya yang telah menyedikan data iklim yang digunakan dalam penelitian ini.

\section{DAFTAR PUSTAKA}

[1] R. G. Allen, L. S. Pereira, D. Raes, and M. Smith, "Crop evapotranspiration - Guidelines for computing crop water requirements FAO Irrigation and drainage paper 56," 1998. [Online]. Available: http://www.fao.org/3/X0490E/x04 $90 \mathrm{e} 00 . \mathrm{htm}$.

[2] K. Beven, "A sensitivity analysis of the Penman-Monteith actual evapotranspiration estimates," J. Hydrol., vol. 44, no. 3-4, pp. 169190, Dec. 1979.

[3] T. K. Manik, R. B. Rosadi, and A. Karyanto, "Evaluation of PenmanMonteith Method in Estimating Standard Evapotranspiration (ET0) in Lowland Area of Lampung Province, Indonesia," J. Keteknikan Pertan., vol. 26, no. 2, pp. 121-128, Oct. 2012.

[4] S. Suprayogi, B. I. Setiawan, and L. B. Prasetyo, "Penerapan beberapa model evapotranspirasi di daerah tropika," Buletin Keteknikan Pertanian, vol. 17, no. 2, pp. 7-13, 2003.

[5] R. Fibriana, Y. S. Ginting, E. Ferdiansyah, and S. Mubarak, "Analisis Besar Atau Laju Evapotranspirasi pada Daerah Terbuka," Agrotekma J. Agroteknologi dan Ilmu Pertan., vol. 2, no. 2, p. 130, Jun. 2018.

[6] J. Zupan, "Introduction to artificial neural network (ANN) methods: what they are and how to use them," Acta Chim. Slov., vol. 41, no. September, pp. 327-327, 1994.

[7] G. Zhang, B. E. Patuwo, and M. Y. $\mathrm{Hu}$, "Forecasting with artificial neural networks: The state of the art," Int. J. Forecast., vol. 14, pp. 3562, 1998.

[8] S. K. Sheikh and M. G. Unde, "SHORT-TERM LOAD FORECASTING USING ANN TECHNIQUE," Int. J. Eng. Sci. Emerg. Technol., vol. 1, no. 2, pp. 97107, Feb. 2012.

[9] S. Suprayogi, B. I. Setiawan, and Suroso, "Estimation of Evapotranspiration Potensial using Artificial Neural Networks," Majalah Geografi Indonesia, no. March 2004, pp. 31-44, 2016.

[10] M. Kalechman, PRACTICAL MATLAB APPLICATIONS FOR ENGINEERS. London: CRC Press Taylor \& Francis Group, 2009.

[11] M. H. Al Shamisi, A. H., and H. A. N. Hejase, "Using MATLAB to Develop Artificial Neural Network Models for Predicting Global Solar Radiation in Al Ain City - UAE," in Engineering Education and Research Using MATLAB, A. Assi, Ed. United Arab Emirates: InTech, 2011, pp. 219-238. 